\title{
Assessing Social Vulnerability to Flood Hazards in the Dutch Province of Zeeland
}

\author{
Ryan H. Kirby ${ }^{1} \cdot$ Margaret A. Reams $^{1} \cdot$ Nina S. N. Lam ${ }^{1} \cdot$ Lei Zou $^{1}$ • \\ Gerben G. J. Dekker ${ }^{2}$ D. Q. P. Fundter ${ }^{3}$
}

Published online: 27 May 2019

(C) The Author(s) 2019

\begin{abstract}
The 2007 European Union Floods Directive encouraged member nations to pursue a more integrated view of flood risks and management strategies, taking into account social vulnerabilities of residents. To date, most flood-risk analyses conducted by the Dutch government have focused on physical risk. This study utilizes fine-scale data to construct a social vulnerability index for 147 districts of the Dutch province of Zeeland, located in the Southwestern Delta and the scene of widespread devastation following the 1953 North Sea Flood. Factor analysis of 25 indicators of social vulnerability selected from related research in Europe and the United States results in seven factors explaining roughly $66 \%$ of the total variance. These factors of social vulnerability in Zeeland are urban density, low-income households, recent population change, female gender, train access, and self-employed and service-sector employment. The index was constructed using the toploading variable in each of these factors, with weights determined by the variance explained by each factor. Scores range from a low of 0.20 in Schore, municipality of Kapelle, to the highest score of 0.64 in Oudelandse Hoeve of Terneuzen. The most vulnerable districts are located in South Zeeland, with eight of the 10 found in Terneuzen. The majority of less vulnerable districts are located in Zeeland's central region.
\end{abstract}

Ryan H. Kirby

rkirby3@1su.edu

1 Department of Environmental Sciences, Louisiana State University, Baton Rouge, LA 70803, USA

2 Climate Studies, Wageningen University \& Research, Wageningen 6708 PB, Gelderland, The Netherlands

3 Delta Management, University of Applied Sciences, Vlissingen 4382 NW, Zeeland, The Netherlands
Keywords Factor analysis - Flood hazards $\cdot$ Netherlands $\cdot$ Social vulnerability index $\cdot$ Southwest Delta $\cdot$ Zeeland

\section{Introduction}

The remarkable flood-control engineering achievements of the Dutch likely will be tested in the years to come. The 2013 Intergovernmental Panel on Climate Change projected a global mean sea-level rise of up to $120 \mathrm{~cm}$ by 2100 (Stocker et al. 2014), and the European Environment Agency forecasted more seasonal precipitation in the European northwest (EEA 2012). Between 1980 and 2010, the Netherlands has suffered from 27 natural hazard-induced disasters (CRED 2010). The most common disaster was storms (18), followed by extreme temperature (4), flooding (3), earthquake (1), and epidemic (1). These events varied greatly in magnitude, but collectively resulted in 2013 deaths and over USD 4.5 billion worth of damage (CRED 2010).

In light of increasing flood hazards, the 2007 European Union Floods Directive ${ }^{1}$ encourages member nations to adopt a more integrated view of flood risks and management strategies, taking into account the social vulnerabilities of residents (Beurton and Thieken 2012). To date, most Dutch flood-risk assessments have focused on physical risk. For example, the most comprehensive disaster impact assessment is the Veiligheid Nederland in Kaart (VNK), or Flood Risk in the Netherlands (VNK2 2012), which takes into account environmental factors such as mean elevation and sea-level rise, along with the likelihood of failures of flood protection structures. A fine-scale social vulnerability

\footnotetext{
${ }^{1} \mathrm{http} / / /$ ec.europa.eu/environment/water/flood_risk/index.htm.
} 
assessment could provide additional insight to support disaster planning, especially at the local level.

Our objectives are to identify associations between key contextual conditions that make Dutch communities more socially vulnerable, and to construct a simple index of key indicators of social vulnerability that could be combined with flood-risk models to inform local decision makers with actionable findings regarding potential strategies for investments intended to reduce social vulnerabilities. Specifically, we aim to: (1) identify indicators of social vulnerability at the level of $w i j k$, or municipal district in the Netherlands; (2) construct a simple social vulnerability index for the municipal districts of one Dutch province, Zealand; and (3) map the index scores to easily identify more socially vulnerable municipal districts.

The resulting case study should provide useful insights for local policymakers and community stakeholders as they consider collective actions to increase the future health and safety of residents of Zeeland Province.

\subsection{Measuring Social Vulnerability}

Social vulnerability refers to the social, economic, demographic, and built characteristics of a community that affect its ability to respond to, cope with, recover from, and adapt to environmental hazards (Cutter et al. 2003; HVRI 2019). In the United States (US), Cutter and colleagues (2003) pioneered methods that assessed social vulnerability at the county level. They selected indicators of economic resources, demographic attributes of residents, and type and density of infrastructure to be aggregated into a single index. Their Social Vulnerability Index (SoVI) applied factor analysis to 42 variables, which clustered along 11 factors accounting for roughly $76 \%$ of the variance among over 3000 US counties.

Building on the SoVI approach and methodology, other researchers have included additional variables, applied the analysis to various geographic scales, and used different statistical analysis and aggregation methods (Cutter and Finch 2008; Schmidtlein et al. 2008; Fekete 2010; Finch et al. 2010; Sherrieb et al. 2010; Tapsell et al. 2010; Holand and Lujala 2013; Chen et al. 2013; Tate 2012). Our research team used similar methods to explore the resilience capacity of 52 US coastal counties along the northern Gulf of Mexico (Reams et al. 2012). In that study, we adapted 36 variables from the US SoVI analysis and added seven more to include government spending, environmental factors such as the US Environmental Protection Agency's Toxic Release Inventory, and mean elevation. The method aimed to improve the statistical analysis offered in Cutter's SoVI, applying principle axis factoring instead of principal component analysis, for a correlationbased approach rather than a variance-based approach
(Reams et al. 2012). While the SoVI method adds factor scores to create essentially an index of an index, selecting the top loading variable of each dimension is a method that offers findings bearing greater actionability than a summed factor score, which may be difficult to interpret. Selecting the top loading variable to represent each dimension may be more logical because principal axis factoring takes a correlation-focused approach that includes all variables before determining their importance rather than the variance-based approach of principal component analysis that uses all variables, seeking both common and unique variance in the data (Reams et al. 2012). Lastly, the additive index aggregation of the SoVI method does not make a priori assumptions about the importance of the factors while eigenvalues offer a statistically determined method to express the importance of each dimension through explained variance (Reams et al. 2012).

Other researchers have examined indicators of economic and social vulnerability among European communities. In Belgium, for example, Coninx and Bachus (2007) combined such indicators with flood risk maps in order to identify communities that are more susceptible. They modified indicators from the Social Flood Vulnerability Index developed by the British Flood Hazard Research Centre (Tapsell et al. 2010). In Norway, researchers compared the results of replication of the SoVI using the same measures developed by Cutter and colleagues in the United States, with measures of social vulnerability selected to be more reflective of conditions in Norway (Holand and Lujala 2013). The two indices calculated for Norwegian municipalities were only moderately correlated, which suggests that contextual factors including the geographic scale of data collected, along with cultural, governmental, and institutional characteristics of a jurisdiction are important considerations in the construction of a social vulnerability index (Holand and Lujala 2013).

In Germany, Fekete (2010) demonstrated an approach to assess and validate social vulnerability for communities along river channels. Fekete's assessment was similar to the index by Coninx and Bachus (2007) and the Bogardi/ Birkmann/Cardona framework (Birkmann 2006), which included indicators of social, economic, and environmental conditions. Fekete applied the analysis to 439 German counties and included 41 indicators of age, gender, ethnic background, education, income, and physical environmental factors. The resulting index was validated through a survey of residents who experienced the 2002 river floods in Germany. Fekete found residents of counties classified as more vulnerable did indeed have more difficulty recovering from the river floods. 


\subsection{Study Area: Zeeland Province}

We selected the Dutch province of Zeeland to demonstrate the construction of a social vulnerability index for several reasons. First, the province contains an interesting mix of land uses, with some areas being predominately agricultural and rural, and others more densely populated and industrialized. Second, its districts and communities vary in terms of wealth, economic vitality, and population growth. Third, there is variation in environmental conditions relevant to future flood exposure and risks, including mean elevations above sea level. Finally, Zeeland Province was the location of major destruction and loss of life following the great North Sea Flood of 1953. That devastation led to the formation of the modern Dutch flood defense program, including the Delta Works network of floodcontrol structures.

The province of Zeeland, shown in Fig. 1, is located on the Southwest Delta (SWD) of the Netherlands, where the Rhine, Meuse, and Scheldt Rivers meet the North Sea. The SWD is a tide-dominated delta with relatively low river discharge. This southernmost coastal Dutch province boasts popular holiday destinations, ecotourism, and a rich history of trade, commerce, and agriculture. Zeeland encompasses $1784 \mathrm{~km}^{2}$ of land and $51 \mathrm{~km}^{2}$ of surface waters and supports a population of roughly 381,400 inhabitants distributed at 214 persons per $\mathrm{km}^{2}$ (CBS 2015). Zeeland contains 13 municipalities, divided into 164 municipal districts (wijk) that divide municipalities into parcels of generally similar land use. For example, heavy industry does not exist within dense residential neighborhoods. The districts of Zeeland tend to be geographically larger and less densely populated than the Dutch national average given the many farms and other extractive-industry enterprises.

Zeeland's land area consists of three delta lobes separated by two estuaries, which provide entry to major European trade arteries. Shipping traffic through the Westerschelde to the Port of Antwerp requires open access through the channel, which is the only Dutch estuary with unmanaged tidal exchange. The Westerschelde exhibits a tidal difference commonly over $4 \mathrm{~m}$ (van den Berg et al. 1995). The fragmented province exhibits great exposure to both coastal and river flooding, with almost one-third of the land below sea level and with an average elevation of only $1.1 \mathrm{~m}$ (Rijkswaterstaat 2014). Figure 1 illustrates Zeeland's land areas below sea level (in blue) relative to buildings (in orange) to visualize population centers and areas of high physical vulnerability due to low elevation.

\section{Data and Methods}

Our analysis applies concepts and indicators of social vulnerability gleaned from related research. We were interested in gathering data at a fine scale in these categories: demographics, social/economic, and infrastructure/community. We constructed the dataset based on the

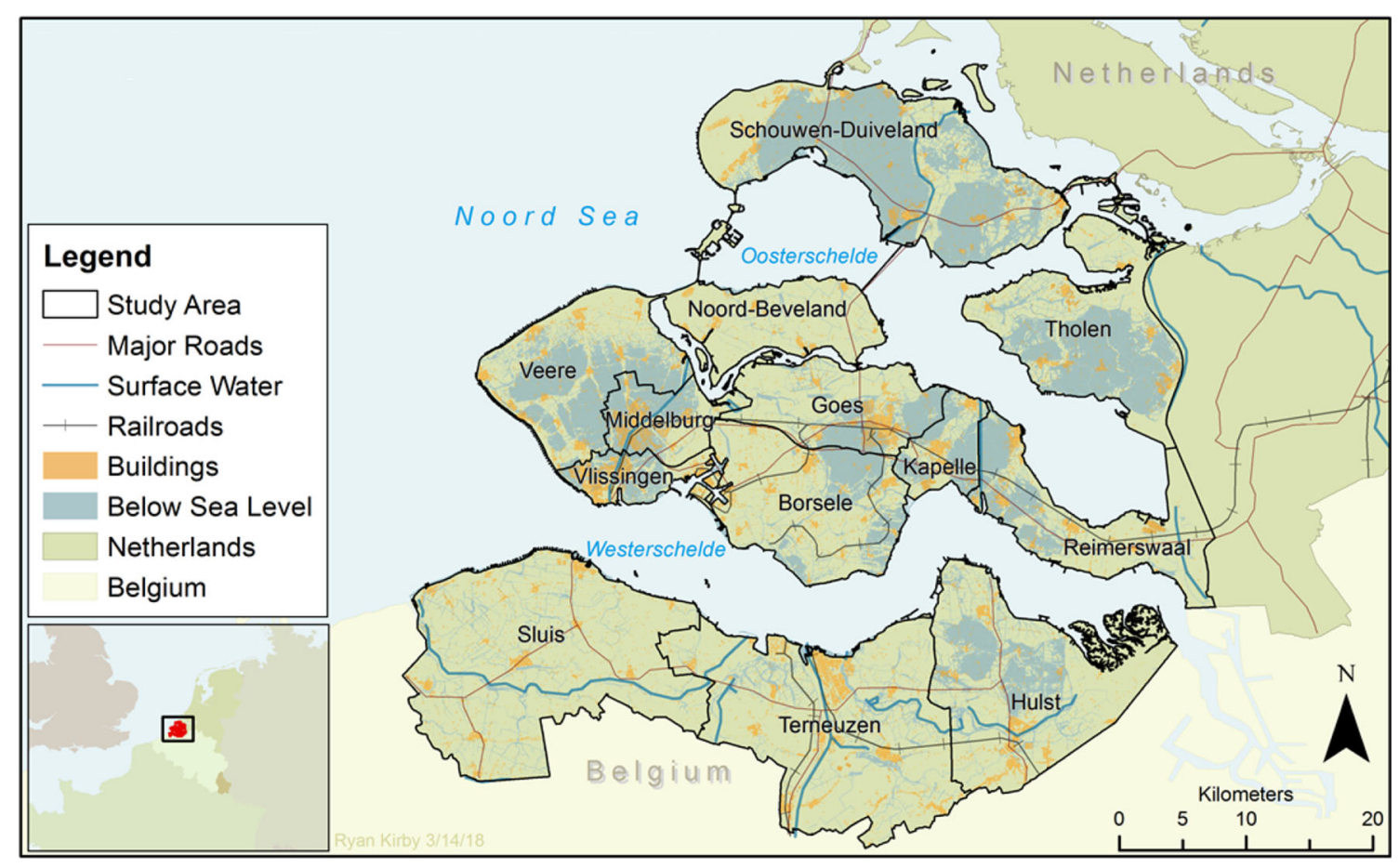

Fig. 1 Study setting in the province of Zeeland, southwestern Netherlands 
concepts of vulnerability identified by Holand and Lujala's Norway social vulnerability index (Holand and Lujala 2013), Fekete's social vulnerability index in Germany (Fekete 2009), and Cutter's social vulnerability to environmental hazards (Cutter et al. 2003). Our aim was to represent all concepts of social vulnerability encountered in the referenced studies. Although the fine scale of analysis created some difficulties in obtaining a wealth of highquality variables, observed relevant adjusted variables similar to Holand and Lujala (2013) were used. For example, Holand and Lujala (2013) include "Old Houses" as a technical adjustment to Cutter's (2003) SoVI key indicator "mobile homes," which are not commonly found in the study area. "Nearby Hotels" was included because the process of recovering from a flood disaster often requires an influx of temporary workers and governmentrelated recovery personnel and temporary housing for individuals/families with property damage. Recovery benefits when an area has greater capacity to house these personnel and victims during reconstruction. The variable "Nearby Hotels" reports the frequency of lodging establishments per capita that occur within $3 \mathrm{~km}$ of the district centroid. The resulting dataset contains 25 indicators of vulnerability in Zeeland at the municipal-district scale. The variables we used in our analysis are listed in Table 1.

The Netherlands provides census data at various scales including the national, provincial, municipal, district, and neighborhood levels. Neighborhood-level data provide a view into small geographic areas but lack completeness and richness in areas outside of city centers. The next level, wijk, or municipal district, provides for more data while retaining a fine geographic scale useful for mapping. Statistics Netherlands (CBS) defines a wijk as "part of a municipality where a specific form of land use or building is predominating e.g. industrial, housing with high or low building (density)" (CBS 2015). The national average size of districts is under $7 \mathrm{~km}^{2}$, although Zeeland contains spatially larger districts (many agricultural) with an average district land mass near $11 \mathrm{~km}^{2}$ (CBS 2015).

The CBS publishes district-level data in a document titled StatLinepublicaties Kerncijfers wijken en buurten (KWB, Key Figures for Districts and Neighborhoods). ${ }^{2}$ The public database reports on the subjects of demographics, employment, living conditions, income, business, work, energy, education, motor vehicles, local amenities, and land use. The Compendium voor de Leefomgeving, ${ }^{3}$ the Environmental Compendium, provides data of highly educated individuals ${ }^{4}$ (CBS et al. 2014). By special

\footnotetext{
$\overline{2}$ https://www.cbs.nl/nl-nl/dossier/nederland-regionaal/wijk-en-buurt statistieken/kerncijfers-wijken-en-buurten-2004-2018.

3 https://www.clo.nl/indicatoren/nl210005-opleidingsniveaubevolking.
}

request, the Rijkswaterstaat (Department of Waterways and Public Works) provided access to the "Top 10" database, which includes information on average elevation, infrastructure, land cover, and administrative boundaries.

Districts lacking sufficient population or development density were problematic. Data suppression is common at small-scale observation in the CBS database, including data fields coded "secret" when populations do not reach a privacy threshold within some land areas. For example, all human information may be coded secret if a neighborhood contains less than 50 total residents. Sensitive data, including income, have population-threshold minimums of 200 per neighborhood. Of the 164 districts in Zeeland, 17 are labelled as problematic districts. The districts lacking sufficient population were excluded from the following analysis, bringing the study sample to $\mathrm{N}=147$ districts.

Potential indicators of vulnerability that lacked sufficient data saturation were removed from the database. The threshold for retaining a variable was it having numeric values for more than $80 \%$ of the cases. Absolute and continuous variables were converted into percent, per capita, or density. The converted dataset was tested in SPSS 22 with regression models to identify potential problems with correlation, low communalities, high cross loadings to reduce redundancy, and to improve the quality of the dataset for analysis. The signs of variables that represent capacities were reversed to represent a vulnerability. For example, the positive sign before the variable "Employment," a capacity, was reversed to portray the condition of unemployment. While more employment is a trait of low vulnerability, more unemployment is a condition of vulnerability for a community. Finally, variables were standardized to satisfy the conditions required for factor analysis.

We used exploratory factor analysis with principal axis factoring in SPSS 22 statistical package to identify patterns of association among the 25 variables. Varimax rotation with Kaiser normalization provides a clear solution for factor assignment and factor weights through perpendicular axis rotation. Factor retention was decided with Kaiser criterion, selecting factors with eigenvalues greater than 1.00. The rotated factor matrix shows dominantly loading variables for each factor. We inverted any variables containing a negative relationship with social vulnerability. The presence of zero values posed the issue of index distortion among inverted variables. To solve this problem, zero density cells were reclassified as the minimum value

\footnotetext{
4 Statistics Netherlands reports Hoogopgeleiden (Highly educated individuals) as the ratio of citizens 15 to 75 with the higher professional education (including associates degree) or academic research education (including a doctoral degree).
} 
Table 1 Zeeland social vulnerability index input variables

\begin{tabular}{|c|c|c|c|c|c|}
\hline \multicolumn{6}{|c|}{ Original variables included in factor analysis } \\
\hline Description & Unit & Mean & SD & Adjustment & Referenced study \\
\hline \multicolumn{6}{|l|}{ Demographics } \\
\hline Female & $\%$ & 0.49 & 0.03 & None & $1,2,3^{\mathrm{a}}$ \\
\hline Foreign Population & $\%$ & 17.55 & 11.74 & None & $1,2,3^{\mathrm{a}}$ \\
\hline Population $65+$ & $\%$ & 19.06 & 6.06 & None & $1,2,3$ \\
\hline Population Change 2003-2012 & $\%$ & 10.40 & 37.54 & Absolute & 1,3 \\
\hline \multicolumn{6}{|l|}{ Social/economic } \\
\hline Average income per capita & $1000 € /$ person & 21.38 & 2.34 & Inverted & $1,2,3$ \\
\hline Average house value & $1000 €$ & 208.24 & 47.17 & Inverted & $1,2^{\mathrm{a}}, 3$ \\
\hline Employment & $\%$ & 74.44 & 5.99 & Inverted & $1,2,3$ \\
\hline Employment service industry & $\%$ & 41.68 & 6.31 & None & 1,3 \\
\hline Employed in health care & $\%$ & 14.11 & 3.17 & Inverted & $1^{\mathrm{a}}, 2^{\mathrm{a}}, 3$ \\
\hline Highly educated individuals & $\%$ & 18.58 & 3.94 & Inverted & 2,3 \\
\hline Low-income households & $\%$ & 37.61 & 7.92 & None & $1^{\mathrm{a}}, 3$ \\
\hline Old houses & $\%$ & 90.86 & 8.93 & None & $1^{\mathrm{a}}, 2^{\mathrm{a}}, 3$ \\
\hline Passenger cars per household & \#/HH & 1.23 & 0.21 & Inverted & $3^{\mathrm{a}}$ \\
\hline Relative disability benefits & \# HH/1000 & 11.41 & 22.01 & None & $1^{\mathrm{a}}, 2,3$ \\
\hline Rental housing & $\%$ & 24.97 & 11.81 & None & 1,3 \\
\hline Self-employed & $\%$ & 12.07 & 5.45 & None & $1^{\mathrm{a}}$ \\
\hline Single person households & $\%$ & 29.27 & 7.94 & None & $2^{\mathrm{a}}$ \\
\hline \multicolumn{6}{|l|}{ Infrastructure/community } \\
\hline Distance to medical services & $\mathrm{km}$ & 10.20 & 5.78 & None & $1^{\mathrm{a}}, 3$ \\
\hline Distance to train station & $\mathrm{km}$ & 25.62 & 16.88 & None & $1,3^{\mathrm{a}}$ \\
\hline Length of major road & $\mathrm{km} / 1000$ pop & 6.67 & 9.52 & Inverted & 2,3 \\
\hline Number of nearby childcare(s) & $3 \mathrm{~km}$ & 2.97 & 3.63 & Inverted & 2 \\
\hline Nearby hotels & $3 \mathrm{~km} / 1000$ pop & 1.09 & 2.85 & Inverted & $\mathrm{n} / \mathrm{a}$ \\
\hline Population density & $\# / \mathrm{km}^{2}$ & 794.37 & 1372.84 & None & 3 \\
\hline Stacked housing & $\%$ & 5.44 & 10.35 & Inverted & $2,3^{\mathrm{a}}$ \\
\hline Total active businesses Jan. 2011 & $\# / \mathrm{km}^{2}$ & 44.69 & 90.71 & None & 1,3 \\
\hline
\end{tabular}

HH Household; pop Population

Referenced studies: 1 = Cutter et al. (2003); 2 = Fekete (2009); 3 = Holand and Lujala (2013)

${ }^{a}$ Adapted (conceptual or geographic)

for the variable to depict an increased vulnerability rather than complete absence.

We constructed the Zeeland social vulnerability index (ZSVI) by selecting one representative variable for each factor, assigning weights based on the variance explained by each factor (rescaled to 100\%), and aggregating the variables (Baker 2009; Reams et al. 2012).

The first seven factors with eigenvalue greater than 1 were identified by the factor analysis and used for further analysis. For each factor, the highest loading variable was selected to calculate the final social vulnerability index. Next, each of the seven variables was normalized through:
$V_{i}=\frac{X_{i}-X_{i \min }}{X_{i \max }-X_{i \min }}$

where $V_{i}$ is the normalized value of variable $X_{i}$, and $X_{i \min }$ and $X_{i \max }$ represent its minimum and maximum values, respectively. Finally, the social vulnerability index was derived by:

$\mathrm{I}=\sum_{i=1}^{7} V_{i} \lambda_{i}$

where $\lambda_{i}$ is the rescaled variance explained to weight the index scores. 
Table 2 Factor analysis results

\begin{tabular}{|c|c|c|c|c|c|c|c|}
\hline \multicolumn{8}{|l|}{ Rotated factor matrix ${ }^{a}$} \\
\hline & \multicolumn{7}{|l|}{ Factor } \\
\hline & 1 & 2 & 3 & 4 & 5 & 6 & 7 \\
\hline$\%$ Population $65+$ & 0.118 & 0.145 & -0.050 & 0.716 & 0.079 & -0.059 & 0.274 \\
\hline$\%$ Female & 0.077 & -0.001 & -0.346 & 0.781 & -0.098 & 0.158 & -0.038 \\
\hline$\%$ Foreign population & 0.274 & 0.210 & 0.231 & 0.034 & 0.639 & 0.094 & 0.025 \\
\hline \%Population change 2003-2012 (ABS) & -0.004 & -0.142 & 0.816 & -0.294 & 0.071 & 0.071 & 0.022 \\
\hline$\%$ Rental housing & 0.403 & 0.587 & 0.161 & 0.335 & -0.106 & 0.276 & 0.206 \\
\hline \%old houses & -0.025 & 0.134 & -0.757 & 0.039 & 0.121 & -0.021 & 0.092 \\
\hline \%Low-income households & 0.259 & 0.730 & -0.053 & 0.267 & 0.359 & -0.042 & 0.226 \\
\hline$\%$ Single person households & 0.464 & 0.485 & -0.200 & 0.451 & 0.089 & 0.089 & 0.309 \\
\hline \%Employment (INV) & 0.189 & 0.442 & 0.539 & -0.102 & 0.290 & 0.198 & 0.151 \\
\hline$\left(\mathrm{km}^{2}\right)$ Population density & 0.819 & 0.198 & -0.043 & 0.120 & 0.151 & 0.257 & -0.089 \\
\hline \%Highly educated individuals (INV) & -0.111 & 0.234 & -0.005 & -0.125 & 0.554 & 0.072 & -0.220 \\
\hline (3 km) Number of nearby childcare(s) (INV) & -0.784 & -0.120 & -0.171 & -0.119 & 0.035 & -0.276 & 0.031 \\
\hline$(\mathrm{km})$ Distance to medical services & -0.611 & 0.116 & -0.125 & 0.035 & 0.084 & 0.039 & 0.078 \\
\hline (1 k HH) Relative disability benefits & 0.198 & 0.343 & 0.592 & 0.057 & 0.069 & -0.253 & -0.169 \\
\hline$\%$ Self-employed & -0.382 & -0.188 & -0.006 & 0.061 & -0.052 & -0.826 & 0.182 \\
\hline$(1000 € \mathrm{PP})$ average income per capita (INV) & -0.106 & 0.656 & -0.091 & -0.013 & 0.004 & 0.227 & -0.123 \\
\hline$\%$ Employment service industry & 0.269 & 0.117 & -0.032 & 0.078 & -0.114 & 0.173 & 0.752 \\
\hline \%Employed in health care (INV) & -0.271 & 0.087 & -0.035 & 0.036 & 0.154 & -0.216 & 0.541 \\
\hline$(1000 €)$ Average house value (INV) & 0.323 & 0.595 & -0.096 & -0.034 & 0.427 & 0.219 & -0.235 \\
\hline$(\mathrm{km})$ distance to train station & -0.188 & -0.165 & -0.114 & 0.092 & 0.886 & -0.187 & 0.131 \\
\hline \# Passenger cars per household (INV) & 0.387 & 0.559 & 0.274 & 0.414 & 0.017 & 0.212 & 0.144 \\
\hline (km PP) Length of major road (INV) & 0.151 & 0.206 & 0.009 & 0.160 & -0.021 & 0.495 & -0.039 \\
\hline$\left(\mathrm{km}^{2}\right)$ Total active businesses Jan. 2011 & 0.730 & 0.152 & -0.037 & 0.030 & 0.019 & 0.093 & 0.022 \\
\hline \%Stacked housing (INV) & -0.707 & -0.252 & -0.080 & -0.408 & 0.011 & -0.167 & -0.084 \\
\hline (1000 PP $3 \mathrm{~km}$ ) nearby hotels (INV) & 0.118 & 0.123 & 0.045 & -0.130 & 0.057 & 0.155 & -0.444 \\
\hline
\end{tabular}

Extraction method: Principal axis factoring; Rotation method: Varimax with Kaiser normalization

$A B S$ Absolute, $H H$ Per household, INV Inverted to align with vulnerability, $P P$ Per person

${ }^{a}$ Rotation converged in 8 iterations

\section{Results and Discussion}

Varimax rotation with Kaiser normalization converged in eight iterations, returning seven factors explaining $66 \%$ of the variance, as summarized in Table 2. Factor loadings observed in the rotated factor matrix indicate the patterns of association or clustering among the variables. The toploading variable for each factor was selected and aggregated to create the ZSVI (Table 3) using Eq. 2.

The Zeeland social vulnerability index ranges from a score of 0.20 in Schore in the municipality of Kapelle, indicating low social vulnerability, to a maximum score of 0.64, indicating high vulnerability, in Oudelandse Hoeve of Terneuzen. The mean score among the districts is 0.36 . District scores applied to the 2012 district boundaries for the 147 districts of Zeeland were mapped using the natural breaks (Jenks) classification method (four classes). Figure 2 illustrates the social vulnerability indices by districts in Zeeland. The scores ranged from low social vulnerability, illustrated in green, to a high level of vulnerability, shown in red. Districts with inadequate data are shown in grey.

\subsection{Factors of Social Vulnerability in Zeeland}

Analyzing the pattern of the data in the rotated matrix aids understanding of how the various indicators of social vulnerability are related to each other. We named each of the seven factors to reflect the common dimension of vulnerability they represent. 
Table 3 Variables for index construction

\begin{tabular}{llccr}
\hline Factor & Highest loading variable per factor & Loading value & Initial variance & Rescaled variance \\
\hline 1 & $\left(\mathrm{~km}^{2}\right)$ population density & 0.82 & 13.76 & 21.01 \\
2 & \%Low-income households & 0.73 & 11.31 & 17.27 \\
3 & \%Population change 2003-2012 (ABS) & 0.82 & 10.82 & 16.52 \\
4 & \%Female & 0.78 & 10.19 & 15.56 \\
5 & \%Self-employed & 0.89 & 9.31 & 14.22 \\
6 & \%Employment service industry & -0.83 & 5.73 & 8.75 \\
7 & & 0.75 & 4.36 & 6.66 \\
& & Total & 65.49 & 100.00 \\
\hline
\end{tabular}

ABS $=$ absolute

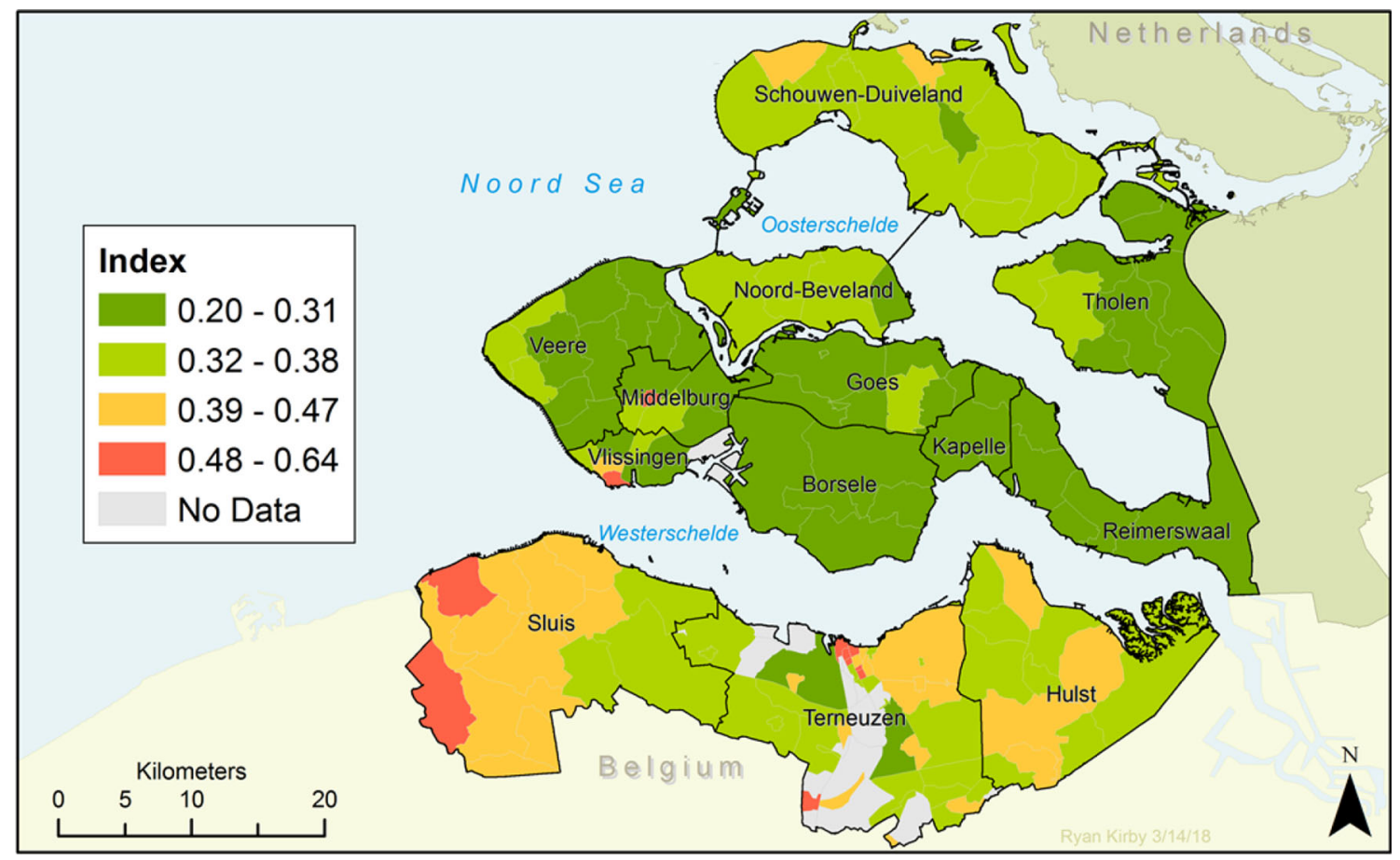

Fig. 2 Social vulnerability index for the province of Zeeland, Netherlands, by districts

\subsubsection{Urban Density}

The highest-loading variable on the first factor is "Population Density," followed by "Total Active Businesses." Additional variables include more childcare facilities and more high rise residential structures. These variables cluster together to represent urban density.

Researchers have found that high-density urban areas may be particularly vulnerable after large-scale disruptive events due to higher potential for economic and commercial losses. For example, Cutter et al. (2003) cited the complications involved with evacuation in high-density urban areas and the financial burden that complex infrastructure repairs can put on recovering communities. The $\mathrm{H}$. John Heinz III Center for Science, Economics, and the
Environment (2002) of Washington, DC identifies the burden placed on families in a disaster situation when essential services such as childcare centers close. Centers of more dense populations may include residents who are dependent on the range of public services that may be disrupted during and after a large-scale flood.

\subsubsection{Low-Income Households}

The second factor represents sources of socioeconomic vulnerability associated with family structure and household economic resources. The top-loading variable for this factor is "\% Low-Income Households." Related attributes include a larger percentage of rental housing, more single- 
person households, lower per capita income and housing value, and fewer passenger automobiles.

The link between these conditions and social vulnerability to large-scale disturbances has been suggested by recent research. For example, Fekete (2010) reported that low-income households and those individuals living alone may have a reduced ability to prepare for and protect themselves during disaster situations. Moreover, households with lower incomes would face a range of difficulties in recovering following a large-scale flood, including inadequate funds to replace lost possessions and property.

\subsubsection{Recent Population Change}

The third factor relates to changes in population within a municipal district from 2003 to 2012. The highest-loading variable is the absolute change in population numbers, either an increase or decrease in recent years. Such a change is in contrast to a more consistent population of residents, wherein social networks and housing patterns may be more stable. While it is intuitive that a rapid population loss may contribute to vulnerability, researchers have noted that population increases also may create challenges to emergency planning and recovery following a large-scale disturbance (Perrow 2007). Population growth may introduce elements of vulnerability if newcomers are not familiar with the flood risks of the area (Donner and Rodriguez 2011). The analysis identified newer housing stock as another variable related to recent population change.

\subsubsection{Female Gender}

The analysis places female gender on the fourth factor. Females may experience a more difficult recovery process due to lower wages and family care responsibilities (Cutter et al. 2003). Dutch females have less of a presence in the full-time work place than men, possibly attributable to the responsibility of raising children. The second highest loading variable here is percentage of people aged 65 and older, indicating a more vulnerable group of residents who may face more obstacles in planning for and recovering from a large flood.

\subsubsection{Train Access}

The fifth factor is characterized by "Distance to Train Station," a variable that represents access to infrastructure necessary for daily transportation and rapid evacuation. The variables of percentage of foreign born population and fewer highly educated residents also load on this factor, indicating additional potential sources of vulnerability. With $40 \%$ of its total area comprised of water, Zeeland's dry land area is fragmented. Further, only about $60 \%$ of residents own personal vehicles, so public rail transportation plays an important role in the lives of the residents. During an emergency evacuation, trains would have the capacity to move large numbers of residents away from the coast. Only one passenger rail line runs through the central lobe of Zeeland; To access that train, residents of the northern and southern lobes must cross water, either by tunnel, bridge, or ferry, introducing potential challenges to residents in the case of a large-scale flood.

\subsubsection{Vulnerable Occupations}

The sixth factor is distinguished by fewer self-employed residents. The category of self-employed may include a wide range of occupations such as agriculture, small business owners, contractors, trade workers, and professional service providers (Eurofound 2017). In the Netherlands, the ranks of the self-employed are increasing and the outlook for new businesses is generally strong, with roughly $74 \%$ surviving the first 2 years (Braams 2010). Cutter et al.'s (2003) US SoVI identifies persons employed in resource-extractive industries, such as farmers, as more vulnerable after a disaster event; but this may not be the case in the Netherlands. Dutch farmers may be somewhat less vulnerable to disruptions in income due to government assistance programs.

The seventh factor is the percentage of the local workforce employed in service industries, not including workers in medical fields. The service workers in the hospitality industries including restaurants, hotels, and shops in tourist towns of the Zeeland may be particularly vulnerable to any disruption in commercial or recreational activities following a large-scale storm or flood.

These seven factors are somewhat similar to other studies. For example, Fekete (2010) derives three factors of social vulnerability, including regional conditions, socioeconomic conditions, and fragility. While "regional conditions" covers concepts of gender, access to healthcare, family/housing conditions, and so on, the highest loading variable on the first factor, population per settlement area, matches the outcome of the Zeeland SVI top-loading first factor variable Population Density. The highest loading variable of our second factor (low-income households) is found loading second highest on Fekete's second component, socioeconomic conditions, along with the Zeeland factor four "Employment" variable. Lastly, the Zeeland index reflects Fekete's third component (fragility) led by population over 65 years old, which is located on the fifth factor for Zeeland.

When comparing results to the Norway SVI, we find greater similarity in the findings, possibly due to the authors' decision to allow for a greater number of factors. 
While the first of the seven factors in the Zeeland SVI groups variables related to urban and high density areas, the Norwegian sorts these conditions independently as the fourth and fifth of 10 components respectively. The second Zeeland SVI factor includes similar variables of components one and seven of the Norwegian SVI, including the grouping of variables related to age and social status and renters, in addition to other variables related to personal wealth. The third factor in the Zeeland SVI includes variables related to unemployment, disability benefits, old houses, and population change. Similar variables may be found in components two and six of the Norwegian SVI, including marginal social groups and demographic instability, respectively.

\subsection{Summary of Results}

The factor analysis of 25 indicators of social vulnerability resulted in seven factors explaining about $66 \%$ of the total variance. The factors of social vulnerability in Zeeland are urban density, low income, population change, more females, distance to train stations, fewer self-employed, and more employed in service industries.

The index presented here considers dense commercial, industrial, and residential areas as containing the highest levels of social vulnerability. The districts of the southern lobe of Zeeland earned the highest scores due to the intersection of multiple factors associated with social vulnerability, which include limited access to lifelines (that is, evacuation routes) and greater foreign population. The six most vulnerable districts are located in the municipality of Terneuzen, bordering the Westerschelde, which is the only unfortified estuary of the Netherlands. The map in Fig. 2 shows the spatial distribution of the social vulnerability scores for the districts of Zeeland Province. Index scores range from a low social vulnerability score of 0.20 in Schore of Kapelle, to the highest social vulnerability score, 0.64 in Oudelandse Hoeve of Terneuzen.

Forty-five of the 50 districts with highest social vulnerability scores are located in South Zeeland, with the top six found in Terneuzen, the most populous municipality in Zeeland. Terneuzen is situated with Belgium to the south and the Westerschelde, a major shipping corridor, to the north. Terneuzen's poorest-scoring district is characterized by high population density, a high proportion of female population, a relatively large number of low-income households, and limited access to lifelines, such as evacuation routes. Terneuzen is home to large-scale chemical industry, and contains several districts reserved strictly for industrial activity, which were omitted from the analysis due to the small resident population of these areas. Terneuzen does not have access to rail, but is connected to the Netherlands by a toll tunnel.
The majority of the districts with lower social vulnerability index scores are located in Zeeland's central region and the municipality of Tholen. Much of the central lobe of Zeeland is prized for tourism and Middelburg, the historic capital of Zeeland, the central lobe and Tholen are serviced by passenger rail, providing critical lifelines to the rest of the Netherlands in the case of an evacuation.

Two districts in the municipality of Kapelle rank in the top 10 lowest social vulnerability index scores, with the third placing just behind, ranked 30. Kapelle is centrally located in the Zeeland, with access to both the Oosterschelde and the Westerschelde, characterized by low population density, stable population relative to change, and nearby access to lifelines.

When we consider the spatial distribution of these social vulnerability scores across the province, several observations can be noted. For example, a high proportion of the elderly population resides in the beach communities of central Zeeland, where towering dunes contribute some of the highest elevations in the province. As a result, the higher elevation may offer flood protection, and thus reduced physical vulnerability to an otherwise socially vulnerable subgroup of the population. Similarly, the Noord-Beveland districts received index scores indicating greater social vulnerability despite relatively high elevation. One contributing factor is due to its role as a tourist destination, and corresponding greater portion of service industry workers. Noord-Beveland does not have access to rail with road access only to the low-lying delta lobes to the north and south.

It is important to point out that factor analysis groups variables together into different factor dimensions based on the similarity in spatial distributions of the variables; it does not necessarily mean that the factors or the selected variables correspond to vulnerability. We interpret how the variables may contribute to social vulnerability within the specific study area based on the findings of related research about sources of social vulnerability. A more objective approach would require validation of the index either through examining empirical damage data (Cai et al. 2016; Lam et al. 2016) or household survey results from those who have experienced large floods as demonstrated in Fekete (2010). Since the flood damage data were not available in the study area (because the study region has not experienced large-scale flooding since 1953), we were not able to verify the derived index.

Our approach is a simplification of the traditional social vulnerability index calculation (Cutter et al. 2003). Instead of computing the combined factor scores and aggregating them into an index, we selected the top-loading variable to represent a factor, and then computed their relative importance and aggregated them into a single vulnerability index. The method can be modified to add two or more 
variables from each factor if desired. This simplified approach is meant to make it easier for planners and managers to identify the specific attributes of communities that may make them more vulnerable and to identify how these attributes are related to other contextual conditions.

The inclusion of proximity to public transportation is a measure unique to this social vulnerability analysis. In the case of Zeeland, where vehicle ownership is relatively low compared to bicycle ownership, residents without easy access to trains or major roadways would not be able to evacuate or recover quickly if faced with a large-scale flood. For example, traveling from Terneuzen to the provincial capital city Middelburg via public transportation requires multiple bus transfers and a ferry crossing, resulting in over an hour of travel time each way to move a relatively short distance. The fragmentation in the landscape in Zeeland Province introduces a significant potential for "bottleneck" delays during an emergency evacuation. Local planners, residents, and other stakeholders could consider investments in additional rail lines and/or other public transportation modes to help reduce the social vulnerability of these communities to future large-scale floods.

\section{Conclusion}

This study has demonstrated a method for assessing social vulnerability at a fine scale in the Dutch province of Zeeland, using readily accessible data. The analysis identified patterns of association between key contextual attributes and conditions that make groups and communities more socially vulnerable. Based on the literature and considering the geographical and institutional relevance of the variables, we selected 25 variables for inclusion in our analysis. A factor analysis was conducted to group the variables into seven dimensions. Then, the top-loading variable from each dimension was used and aggregated into the Zeeland social vulnerability index. The results show that districts in the southern part of Zeeland generally have higher vulnerability to flood hazards. This type of analysis can help policymakers and community stakeholders gain insight into the associations between key factors that could make communities more socially vulnerable, and how those factors are spatially distributed. When used to augment physical flood-risk assessments, a social vulnerability index based on local factors sheds light on the potential impacts, recovery challenges, and realistic risk-reduction strategies that could be adopted in the environmentally vulnerable Southwest Delta of the Netherlands.

Acknowledgements This research was supported by the "Resilient Deltas" RAAK Public Grant, through the HZ University of Applied Sciences, the Netherlands.
Open Access This article is distributed under the terms of the Creative Commons Attribution 4.0 International License (http://crea tivecommons.org/licenses/by/4.0/), which permits unrestricted use, distribution, and reproduction in any medium, provided you give appropriate credit to the original author(s) and the source, provide a link to the Creative Commons license, and indicate if changes were made.

\section{References}

Baker, A. 2009. Creating an empirically derived community resilience index of the Gulf of Mexico region. M.S. thesis. Baton Rouge: Department of Environmental Sciences, Louisiana State University.

Berg, J.H. van den, N.E.M. Asselman, and G.G. Ruessink. 1995. Hydraulic roughness of tidal channel bedforms, Westerschelde estuary, the Netherlands. In Tidal signatures in modern and ancient sediments, ed. B.W. Flemming, and A. Bartholomä, 19-32. Utrecht: Blackwell.

Beurton, S. and A. Thieken, A. 2012. Key findings of research related to: Flood resilient communities - Managing consequences of flooding. 2nd Crue Funding Initiative on Flood Resilient Communities Synthesis Report. http://temis.documentation. developpement-durable.gouv.fr/docs/Temis/0078/Temis0078003/20664_synthese.pdf. Accessed 12 Apr 2019.

Birkmann, J. 2006. Risk and vulnerability indicators at different scales: Applicability, usefulness and policy implications. Environmental Hazards 7(1): 20-31.

Braams, N. 2010. From self-employed to employed. The Hague/ Heerlen: Statistics Netherlands.

Cai, H., N.S.N. Lam, L. Zou, Y. Qiang, and K. Li. 2016. Assessing community resilience to coastal hazards in the lower Mississippi River basin. Water 8(2): 46.

CBS (Centraal Bureau voor de Statistiek/Statistics Netherlands). 2015. Explanation of district and neighborhood figures 2012, 2013, and 2014 (Toelichting Wijk-en Buurtkaart 2012, 2013, en 2014). Den Haag: Centraal Bureau voor de Statistiek. https:// www.cbs.nl/-/media/imported/documents/2015/06/2015-toelicht ing-wijk-en-buurtkaart-2012-2014.pdf?la=nl-nl. Accessed 9 May 2019 (in Dutch).

CBS (Centraal Bureau voor de Statistiek/Statistics Netherlands), PBL (Planbureau voor de Leefomgeving/Netherlands Environmental Assessment Agency), RIVM (Rijksinstituut voor Volksgezondheid en Milieu/Netherlands National Institute for Public Health and the Environment), and WUR (Wageningen University \& Research). 2014. Highly educated, 2013 (Hoogopgeleiden, 2013) (indicator 2100, version 05, 18 July 2014). https://www.clo.nl/ indicatoren/n1210005-opleidingsniveau-bevolking. Den Haag: CBS; PBL. Wageningen: WUR (in Dutch).

Chen, W., S.L. Cutter, C.T. Emrich, and P. Shi. 2013. Measuring social vulnerability to natural hazards in the Yangtze River Delta region, China. International Journal of Disaster Risk Science 4(4): 169-181.

Coninx, I., and K. Bachus. 2007. Integrating social vulnerability to floods in a climate change context. Leuven: Higher Institute for Labour Studies, Catholic University of Leuven. https://www. newater.uni-osnabrueck.de/caiwa/data/papers\%20session/D3/ Coninx\%20and\%20Bachus.pdf. Accessed 10 May 2019.

CRED (Centre for Research on the Epidemiology of Disasters). 2010. EM-DAT. The International Disaster Database. Université catholique. http://emdat.be/. Accessed 17 Oct 2016.

Cutter, S.L., and C. Finch. 2008. Temporal and spatial changes in social vulnerability to natural hazards. Proceedings of the National Academy of Sciences 105(7): 301-306. 
Cutter, S.L., B.J. Boruff, and W.L. Shirley. 2003. Social vulnerability to environmental hazards. Social Science Quarterly 84(2): 242-261.

Donner, W., and H. Rodriguez. 2011. Disaster risk and vulnerability: The role and impact of population and society. Washington, DC: Population Reference Bureau. https://www.prb.org/disaster-risk/. Accessed 12 Apr 2019.

EEA (European Environmental Agency). 2012. Climate change, impacts and vulnerability in Europe 2012: An indicator-based report. Copenhagen: European Environment Agency.

Eurofound (European Foundation for the Improvement of Living and Working Conditions). 2017. The many faces of self-employment in Europe. https://www.eurofound.europa.eu/publications/blog/ the-many-faces-of-self-employment-in-europe.pdf. Accessed Oct 2017.

Fekete, A. 2009. Validation of a social vulnerability index in context to river-floods in Germany. Natural Hazards and Earth System Sciences 9(2): 393-403.

Fekete, A. 2010. Assessment of social vulnerability for river-floods in Germany. Doctoral thesis. Bonn: United Nations UniversityInstitute for Environmental and Human Security (UNU-EHS).

Finch, C., C.T. Emrich, and S.L. Cutter. 2010. Disaster disparities and differential recovery in New Orleans. Population and Environment 31(4): 179-202.

Holand, I.S., and P. Lujala. 2013. Replicating and adapting an index of social vulnerability to a new context: A comparison study for Norway. The Professional Geographer 65(2): 312-328.

HVRI (Hazards and Vulnerability Research Institute). 2019. Social vulnerability index: Frequently asked questions. http://artsands ciences.sc.edu/geog/hvri/faq. Accessed 10 May 2019.

H. John Heinz III Center for Science, Economics, and the Environment. 2002. Human links to coastal disasters. Washington, DC: The H. John Heinz III Center for Science, Economics and the Environment.
Lam, N.S.N., M. Reams, K. Li, C. Li, and L.P. Mata. 2016. Measuring community resilience to coastal hazards along the northern Gulf of Mexico. Natural Hazards Review 17(1): Article 04015013.

Perrow, C. 2007.The next catastrophe. Princeton, NJ: Princeton University Press.

Reams, M.A., N.S.N. Lam, and A. Baker. 2012. Measuring capacity for resilience among coastal counties of the U.S. northern Gulf of Mexico region. American Journal of Climate Change 1(4): 194-204.

Rijkswaterstaat. 2014. AHN2 TOP10NL. Delft: Rijkswaterstaat Centrale Informatievoorziening.

Schmidtlein, M.C., R.C. Deutsch, W.W. Piegorsch, and S.L. Cutter. 2008. A sensitivity analysis of the social vulnerability index. Risk Analysis 28(4): 1099-1114.

Sherrieb, K., F.N. Norris, and S. Galea. 2010. Measuring capacities for community resilience. Social Indicators Research 99(2): 227-247.

Stocker, T., D. Qin, G.-K. Plattner, M. Tignor, S.K. Allen, J. Boschung, A. Nauels, Y. Xia, et al. (eds.). 2014. Climate change 2013: The physical science basis. Working Group I contribution to the Fifth Assessment Report of the Intergovernmental Panel on Climate Change. New York: Cambridge University Press.

Tapsell, S., S. McCarthy, H. Faulkner, and M. Alexander. 2010. Social vulnerability to natural hazards. State of the art report from CapHaz-Net's WP4. London: CapHaz-Net Consortium.

Tate, E. 2012. Uncertainty analysis for a social vulnerability index. Annals of the Association of American Geographers 103(3): 526-543.

VNK2 (Veiligheid Nederland in Kaart 2). 2012. Flood risk in the Netherlands. Translated by Sue McDonnell Translation. Utrecht: VNK2 Project Office. https://www.helpdeskwater.nl/publish/ pages/131663/vnk-rapport-eng-lr.pdf. Accessed 9 May 2019. 